\title{
Optimal Operation of Smart Distribution Networks using Gravitational Search Algorithm
}

\author{
Surender Reddy Salkuti \\ Department of Railroad and Electrical Engineering, Woosong University \\ Daejeon, Republic of Korea.
}

\begin{abstract}
This paper proposes a methodology for an optimal operation of smart distribution network considering the network reconfiguration, distributed generation (DG) units allocation and optimally placing the shunt capacitors for reactive power compensation. In this work, the total power losses minimization objective is considered. By optimizing this objective, it can also results in the reduction of voltage deviation. The proposed problem is solved using evolutionary-based gravitational search algorithm (GSA). Simulation studies are performed on 33 bus radial distribution system (RDS). Simulation results reveal that there is a drastic reduction in the power losses by utilizing the network reconfiguration, DG allocation, and reactive power compensation.
\end{abstract}

Keywords-Distributed generation; renewable energy; metaheuristic algorithms; network reconfiguration; smart grid; reactive power compensation

\section{INTRODUCTION}

Distribution system is the most important component of current smart power system, and it aims to provide the electricity to its customers in an efficient, reliable, economic, and environmentally friendly way while satisfying all the operating constraints of the system. It can be observed that during the last few years, there is a rapid expansion of power systems due to the drastic increase in the load demand which leads to high power losses and poor voltage regulation. To overcome this increased load demand and economic benefits, renewable energy has been introduced to the power system. In recent years, distributed generations (DGs) are emerging as an important alternative solution for the enhancement of smart power distribution systems [1]. Along with this, reactive power compensation and optimal network reconfiguration (ONR) are considered as the tools for the enhancement of smart power distribution systems.

Various objectives considered for the optimal reconfiguration of smart systems include investment and operational cost minimization, active power loss minimization, enhancement of reliability, etc. Several researchers proposed various approaches to handle the distribution networks include optimal network reconfiguration (ONR), optimal allocation of DG, and simultaneous optimization of both ONR and DG allocation. ONR is an approach to change the configuration of distribution system by changing the opening/closing status of the sectionalizing (normally closed) and the tie (normally open) switches of the network, so that the radiality and connectivity are well maintained [2]. The distribution networks need to be expanded to meet the increasing demand, however, it is a big issue as it is associated with various economic and environmental factors. In this situation, ONR is a viable solution to this problem [3, 4]. ONR problem is a highly nonlinear, complex, mixed-integer, large-scale, combinatorial, non-differential, and constrained optimization problem.

The author in [5] proposes an approach for the economic operation of distribution networks by considering the curtailment costs. A multi-objective-based ONR is proposed in [6] for the minimization of loss and enhancement of voltage profile. A day-ahead ONR model is proposed in [7] for smart distribution networks including the renewables-based DGs and storage systems by considering voltage deviations and operating cost minimization objectives. The author in [8] proposes an approach for calculating the daily profit and risk of RDSs by considering the uncertainties of power outputs from the DG units and electricity prices. An analytical optimization approach is proposed in [9] for optimal investment of DG units along with capacitors to minimize interconnection costs of renewable sources and to enhance the voltage profile of the system. An approach for simultaneous ONR and optimal DG allocations in a RDS by considering the voltage stability improvement and active power loss minimization objectives has been proposed in [10]. Simultaneous and optimal allocation of RESs and reconfiguration in RDSs with reliability enhancement and cost of power losses minimization objectives are solved by using the information gap decision theory has been proposed in [11]. The ONR and supply restoration approach based on the improved genetic algorithm (GA) has been proposed in [12]. Multi-criteria based ONR of RDS considering reliability, stability improvement, and loss minimization objectives have been proposed in [13].

The above literature review revealed that there is a need for simultaneous optimization of ONR, reactive power compensation, and optimal allocation of DG units. To address the complexity and computational burden involved with the loss minimization objective, it uses the gravitational search algorithm (GSA). The work presented in this paper is as follows: Distribution load flow (DLF) analysis of the radial distribution system (RDS) has been presented in Section 2. The proposed optimal network reconfiguration (ONR) approach has been presented in Section 3. In Section 4, gravitational search algorithm (GSA) is described. In Section 5,33 bus RDS is used to demonstrate the proposed approach and analyze the results for the considered test system. Finally, conclusions are drawn from the proposed study are reported in Section 6. 


\section{DistRIBUTION LOAD FLOW (DLF)}

Load flow analysis is a tool for steady-state analysis of the distribution network in both operational and planning stages. In the literature, several researchers use conventional approaches like Fast Decoupled, Newton Raphson load flow approaches to address static and dynamic distribution network problems [14]. However, these load flow approaches are inefficient due to high resistance to reactance $(\mathrm{R} / \mathrm{X})$ ratio of the distribution line and its radial structure, which has resulted in the development of special load flows for the RDSs [15]. Most of the load flow calculations are based on forwardbackward sweep methods. The load flow approach presented in this paper is based on an iterative approach which is based on the receiving end voltage of the RDS. Here, an effective power at each bus is calculated after the formulation of the adjacent node and adjacent branch matrices. Fig. 1 depicts the equivalent circuit of a line in a RDS [16].

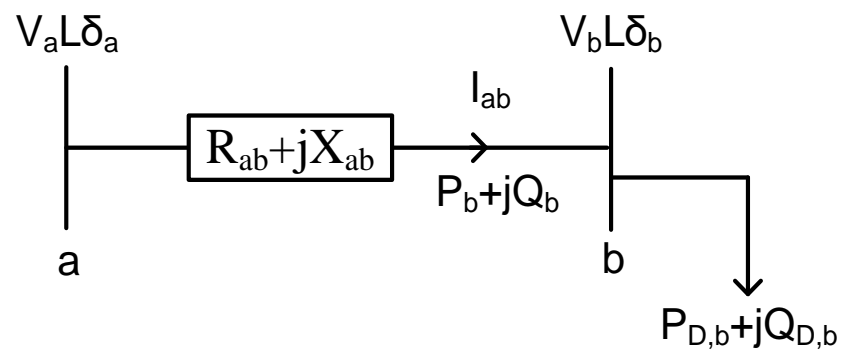

Fig. 1. Equivalent Circuit of a Branch in RDS.

The current in the branch (ab) connected between the sending end (a) and receiving end (b) can be expressed by [16],

$I_{a b}=\frac{\left|V_{a}\right| \angle \delta_{a}-\left|V_{b}\right| \angle \delta_{b}}{R_{a b}+j X_{a b}}=\frac{P_{b}-j Q_{b}}{\left(\left|V_{b}\right| \angle \delta_{b}\right)^{*}}$

Where,

$P_{b}=\sum_{i=1}^{N_{b}} P_{D, i}+\sum_{l=1}^{B_{b}} P_{\text {loss }, l}$

$N_{b}$ represents all the nodes beyond node $\mathrm{b}$ and $B_{b}$ represents all the branches beyond node b. $P_{D, i}$ is power demand at node $i$, and $P_{\text {loss, } l}$ is active power loss in the branch $l$. From equation (1), the active power $\left(P_{b}\right)$ can be calculated by [17],

$P_{b}=\frac{\left|V_{a}\right|\left|V_{b}\right| \sin \left(\delta_{a}-\delta_{b}\right)+R_{a b} Q_{b}}{X_{a b}}$

From equation (3), the voltage at the receiving end can be determined by,

$\left|V_{b}\right|=-\left[\left|V_{a}\right|\left(\frac{R_{a b}}{x_{a b}} \sin \delta-\cos \delta\right)\right]+\left[\left|V_{a}\right|\left(\frac{R_{a b}}{x_{a b}} \sin \delta-\right.\right.$

$\cos \delta)]^{2}-4 Q_{b} \sqrt{\left(\frac{R_{a b}^{2}}{X_{a b}}+X_{a b}\right)}$

Where $\delta=\delta_{a}-\delta_{b}$. The angle $\delta_{b}$ can be expressed by,

$\delta_{b}=\delta_{a}-\tan ^{-1}\left[\frac{P_{b} X_{a b}-Q_{b} R_{a b}}{\left|V_{b}\right|^{2}+P_{b} R_{a b}+Q_{b} X_{a b}}\right]$

The real and reactive power losses in a branch (ab) can be determined by [17],

$$
\begin{aligned}
& P_{\text {loss }, a b}=\frac{R_{a b}\left(P_{b}^{2}+Q_{b}^{2}\right)}{\left|V_{b}\right|^{2}} \\
& Q_{\text {loss }, a b}=\frac{X_{a b}\left(P_{b}^{2}+Q_{b}^{2}\right)}{\left|V_{b}\right|^{2}}
\end{aligned}
$$

\section{PROBLEM Formulation}

Integration of renewable power generation along with ONR is performed to achieve optimum power losses in the system. As mentioned earlier, minimization of total power loss $\left(P_{T}^{\text {loss }}\right)$ in the RDS is selected as a primary objective of ONR problem [18, 19]. However, the problem is also carried out with the objectives of voltage profile improvement, loadability and power quality enhancement, minimization of total network cost and emissions, economic and reliable operation. Real and reactive power losses in a branch connected between the nodes/buses a and b can be expressed by,

$P_{a, b}^{l o s s}=\left(\frac{P_{a, b}^{2}+Q_{a, b}^{2}}{\left|V_{a}\right|^{2}}\right) \times R_{a, b}$

$Q_{a, b}^{l o s s}=\left(\frac{P_{a, b}^{2}+Q_{a, b}^{2}}{\left|V_{a}\right|^{2}}\right) \times X_{a, b}$

Then total power losses $\left(P_{T}^{\text {loss }}\right)$ in the entire RDS can be expressed as [20],

$P_{T}^{\text {loss }}=\sum_{a=1}^{N_{B}}\left(\frac{P_{a, b}^{2}+Q_{a, b}^{2}}{\left|V_{a}\right|^{2}}\right) \times R_{a, b}$

Where $N_{B}$ is number of buses in the RDS.

The power loss minimization objective can be expressed by [21],

$f=\operatorname{minimize}\left(P_{T}^{\text {loss }}\right)$

In this work, optimization is performed, by considering the network reconfiguration, reactive power compensation by using the shunt capacitors, and by optimally allocating the DG units [22], then there is a minimization in the voltage deviation in the system. This voltage deviation can be expressed as,

$\Delta V=\left(\frac{V_{1}-V_{a}}{V_{1}}\right) \quad a=1,2, \ldots, N_{B}$

The above problem is solved by considering the following constraints.

\section{A. Equality Constraints}

These constraints are expressed as [23],

$P_{D}=P_{G}^{G r i d}+\sum_{i=1}^{N_{D G}} P_{D G, i}$

$Q_{D}=Q_{G}^{G r i d}+\sum_{i=1}^{N_{D G}} Q_{D G, i}+\sum_{j=1}^{N_{r c}} Q_{R C, j}$

\section{B. Inequality Constraints}

These constraints for the RDS are DG power limits, bus voltage, and branch current limits.

1) DG power constraints: The real and reactive power generations from DG units [24] are limited by,

$P_{D G, i}^{\min } \leq P_{D G, i} \leq P_{D G, i}^{\max }$ 
$Q_{D G, i}^{\min } \leq Q_{D G, i} \leq Q_{D G, i}^{\max }$

2) Bus voltage constraint: Lower and upper voltage limits of buses in the RDS are expressed as [25],

$V_{B u s, i}^{\min } \leq V_{\text {Bus }, i} \leq V_{B u s, i}^{\max } \quad i=1,2, \ldots, N_{\text {Bus }}$

3) Bus voltage constraint: The current in each branch $\left(I_{b, k}\right)$ is limited by,

$I_{b, k} \leq I_{b, k}^{\max } \quad k=1,2, \ldots, N_{B r}$

4) Power flow constraint: Power loss in each feeder $\left(P_{i}\right)$ is limited by,

$P_{i} \leq P_{i}^{\max } \quad$ for $i=1,2, \ldots, N_{F}$

Where $N_{F}$ is number of feeders in the system.

5) Capacitor constraint: The capacity of shunt capacitor $\left(C_{k}\right)$ is limited by,

$C_{k}^{\min } \leq C_{k} \leq C_{k}^{\max } \quad$ for $k=1,2, \ldots, N_{\text {Cap }}$

Where $N_{C a p}$ is number of capacitor banks. $C_{k}^{\min }$ and $C_{k}^{\max }$ are minimum and maximum values of discrete controls of $k^{\text {th }}$ capacitor banks.

The above problem is solved by retaining the structure of radial network. From an optimization perspective, these problems are considered as highly non-linear, highly constrained, mixed-integer, high dimension, and multi-modal optimization problems with a large number of local optimum solutions. So, determining the global solution is a complex optimization problem is challenging, which provides ample opportunity for further research. The distributed generators (DGs) can be wind energy generators, solar PV, biomass, small hydro, etc.

\section{Gravitational Search Algorithm (GSA)}

GSA has been developed by E. Rashedi et al. in 2009 [26] by using Newton's law of gravity and motion. The gravitational force $(\mathrm{F})$ can be expressed as,

$F=G \frac{m_{1} m_{2}}{r^{2}}$

Where $G$ is gravitational constant. $m_{1}, m_{2}$ are masses of the objects 1 and 2; $r$ is distance between centers of masses. In this GSA, agents are represented as objects and their performance is measured by their masses. Let a system has $N_{m}$ number of masses and the position of $\mathrm{i}^{\text {th }}$ mass $\left(X_{i}\right)$ can be expressed as,

$X_{i}=\left(x_{i}^{1}, x_{i}^{2}, \ldots, x_{i}^{d}, \ldots, x_{i}^{n}\right) \quad i=1,2, \ldots, N_{m}$

Where $n$ is size of search space, $x_{i}^{d}$ is position of $i^{\text {th }}$ mass in $\mathrm{d}^{\text {th }}$ dimension. The flow chart of GSA is presented in Fig. 2. For detailed description of GSA, the reader may refer [26][29].

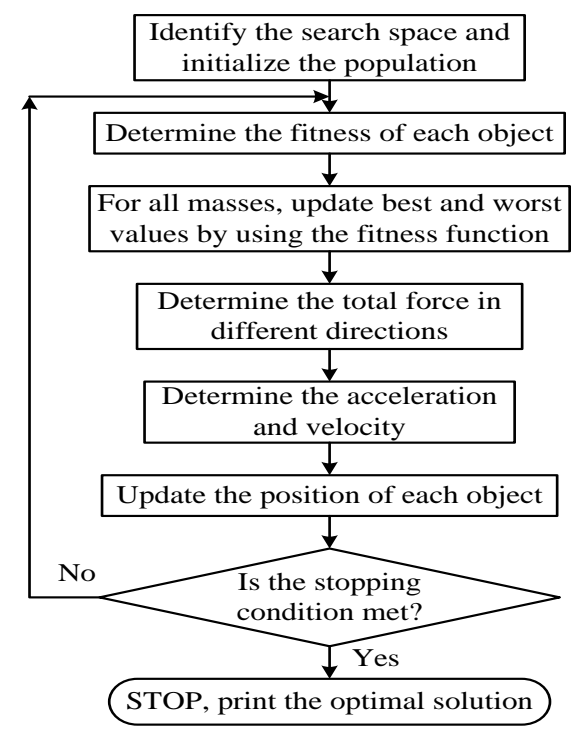

Fig. 2. Flow Chart of GSA.

\section{RESULTS AND DISCUSSION}

In this work 33 bus RDS is used for the analysis and explanation of network reconfiguration. The base voltage and base MVA for 33 bus is considered as $12.66 \mathrm{kV}$ and 100 MVA [30]. In this test system, a maximum of three DG units are incorporated and the maximum size of DG is $2000 \mathrm{~kW}$. In this paper, 3 case studies are considered, and they are:

- Case 1: Optimal operation with only reconfiguration.

- Case 2: Optimal operation with only reactive power compensation.

- Case 3: Optimal operation with only DG allocation.

- Case 4: Optimal operation with reconfiguration, reactive power compensation, and DG allocation.

This test system data has been has been taken from the [31, 32]. This test system has 33 buses, 32 lines, and bus 1 is assigned as the substation bus. In this test system, the active and reactive power demands are $3715 \mathrm{~kW}$ and $2300 \mathrm{kVAr}$. Single line diagram (SLD) of 33 bus system is depicted in Fig. 3 . This system has 5 open tie switches which form the loops in the system and they are 33 to 37 . This system has 32 sectionalizing switches marked as 1 to 32 which are normally closed and they are shown in Fig. 3.

\section{A. Case 1}

As mentioned earlier, a similar analysis can be made for a 33 bus RDS. Initial and final configurations of the system are depicted in Fig. 3 and 4. A comparison of node voltages before and after the reconfiguration is shown in Fig. 5. A comparison of various other parameters before and after reconfiguration is shown in Table I. Under the base case condition (i.e., before the network reconfiguration), the switches 33 to 37 are opened and the system power losses are $202.6592 \mathrm{~kW}$. The minimum voltage has occurred at bus 18 and its value is 0.9038 p.u. 


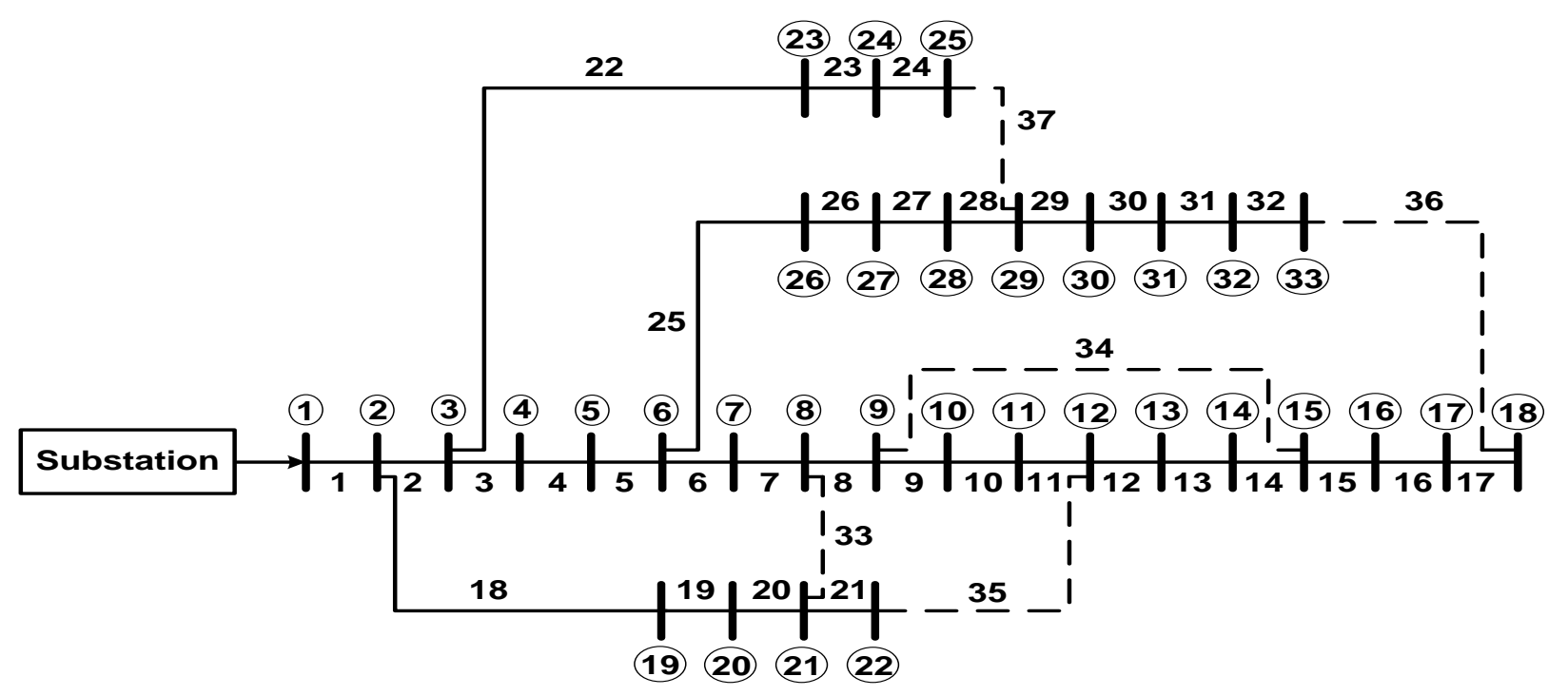

Fig. 3. Initial Configuration of a 33 Bus RDS.

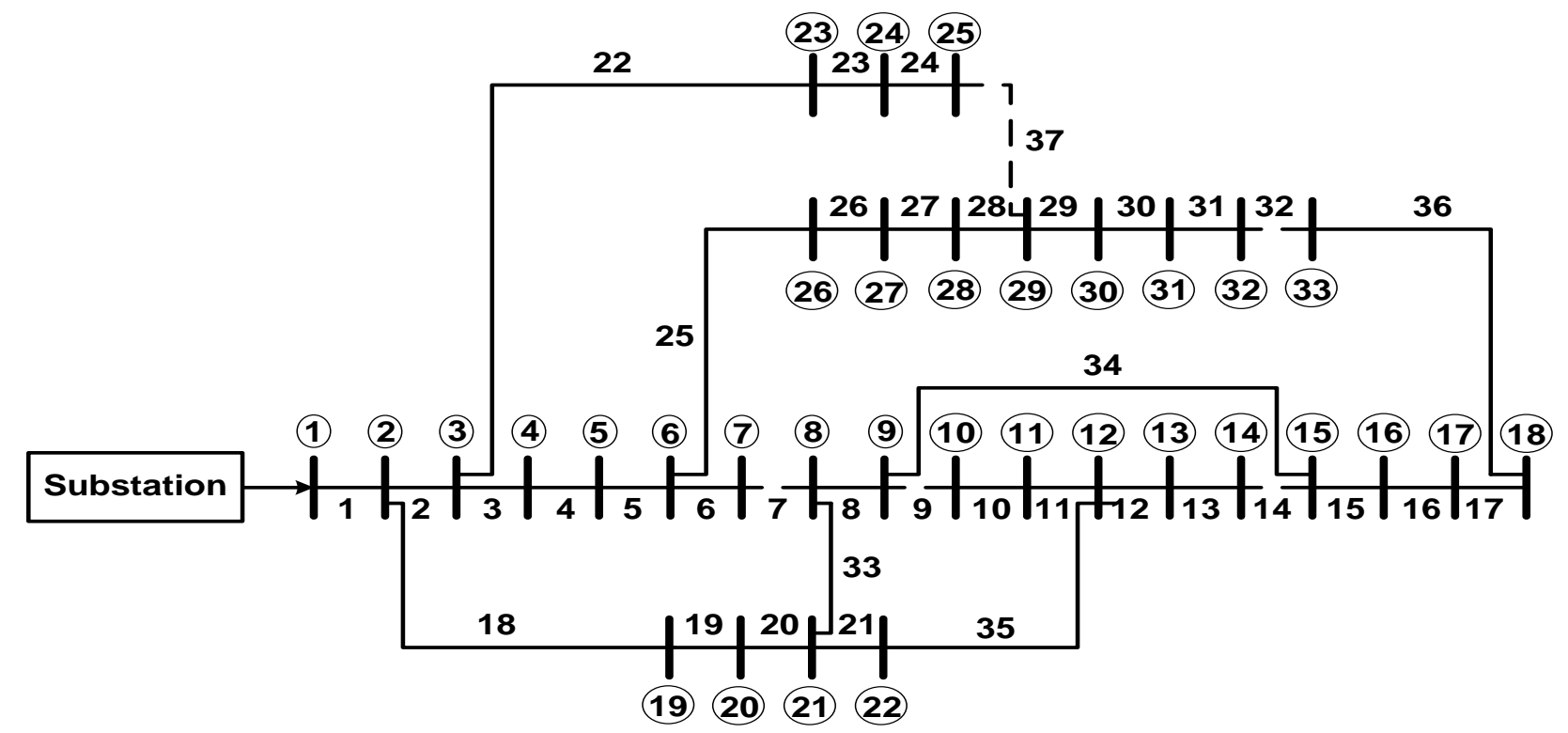

Fig. 4. Final Configuration of a 33 Bus RDS for Case 1.

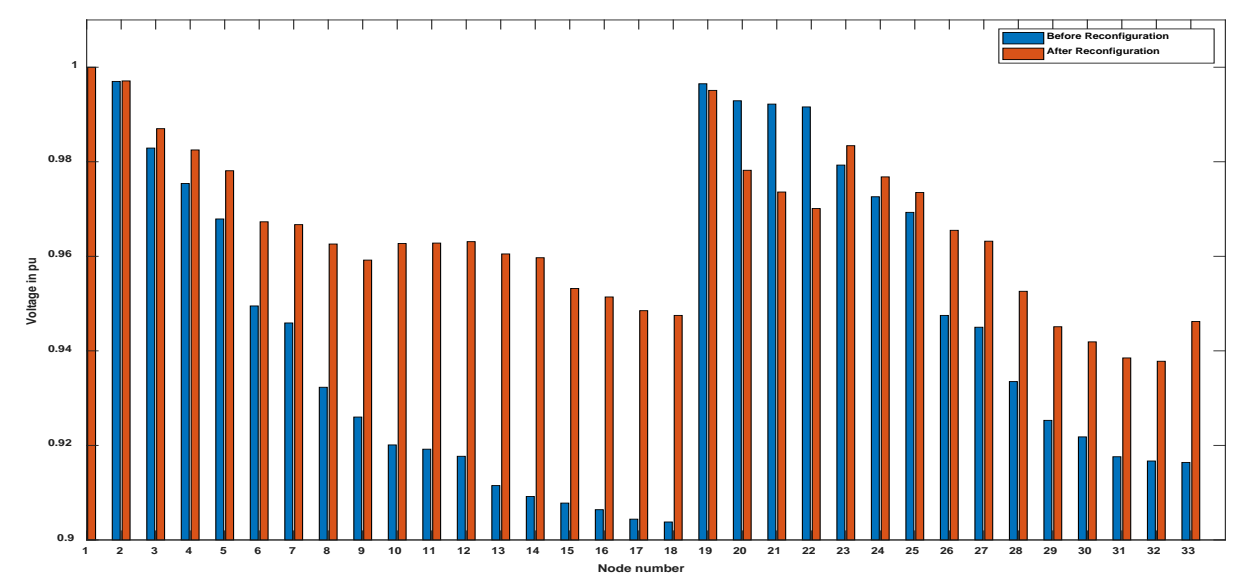

Fig. 5. Comparison of Node Voltages before and after Reconfiguration (Case 1) for a 33 Bus RDS. 
TABLE I. SIMULATION RESULTS FOR 33 BUS RDS BEFORE AND AFTER THE NETWORK RECONFIGURATION

\begin{tabular}{|l|l|l|}
\hline & $\begin{array}{l}\text { Before network } \\
\text { reconfiguration }\end{array}$ & $\begin{array}{l}\text { After network } \\
\text { reconfiguration }\end{array}$ \\
\hline $\begin{array}{l}\text { Tie switches opened for } \\
\text { reconfiguration }\end{array}$ & $33,34,35,36,37$ & $7,9,14,32,37$ \\
\hline Power loss (kW) & $202.6592 \mathrm{~kW}$ & $150.8846 \mathrm{~kW}$ \\
\hline $\begin{array}{l}\text { Reduction in power loss } \\
\text { (\%) }\end{array}$ & - & $25.55 \%$ \\
\hline Minimum voltage (p.u.) & 0.9038 pu at bus 18 & 0.9378 pu at bus 32 \\
\hline
\end{tabular}

From Fig. 5, it can be seen that the voltages at node numbers 5 to 18 and 26 to 33 have drastically improved and at several other nodes, the voltage is improved to a reasonable extent. Though there is a decrease in voltages at some nodes, it is to a reasonable extent. From Table I it can be seen that there is a reduction in active power loss of $25.55 \%$. The minimum voltage after reconfiguration is found to be 0.9378 p.u.

\section{B. Case 2}

In this case, reactive power compensation is used to reduce active power losses further. Table II presents the simulation results for 33 bus RDS for reactive power compensation using differential evolution (DE) and GSA.
TABLE II. RESULTS FOR 33 BUS RDS FOR REACTIVE POWER COMPENSATION USING DE AND GSA

\begin{tabular}{|c|c|c|}
\hline & $\begin{array}{l}\text { Reactive power } \\
\text { compensation using } \\
\text { DE }\end{array}$ & $\begin{array}{l}\text { Reactive power } \\
\text { compensation using } \\
\text { GSA }\end{array}$ \\
\hline \multirow{3}{*}{$\begin{array}{l}\text { Bus number and } \\
\text { reactive power } \\
\text { compensation (kVAr) }\end{array}$} & $552.4 \mathrm{kVAr}$ at bus 6 & $550.4 \mathrm{kVAr}$ at bus 6 \\
\hline & $560.5 \mathrm{kVAr}$ at bs 28 & $562.8 \mathrm{kVAr}$ at bs 28 \\
\hline & $545.9 \mathrm{kVAr}$ at bus 29 & $548.5 \mathrm{kVAr}$ at bus 29 \\
\hline Total compensation & $1658.8 \mathrm{kVAr}$ & 1661.7 kVAr \\
\hline $\begin{array}{l}\text { Power loss before the } \\
\text { compensation }\end{array}$ & $202.6592 \mathrm{~kW}$ & $202.6592 \mathrm{~kW}$ \\
\hline $\begin{array}{l}\text { Power loss after the } \\
\text { compensation }\end{array}$ & $142.52 \mathrm{~kW}$ & $140.83 \mathrm{~kW}$ \\
\hline Power loss reduction & $29.68 \%$ & $30.51 \%$ \\
\hline Minimum voltage & $0.9794 \mathrm{pu}$ at bus 33 & $\begin{array}{l}0.9798 \text { pu at buses } 17 \\
\text { and } 33\end{array}$ \\
\hline
\end{tabular}

Active power losses before reactive power compensation is $202.6592 \mathrm{~kW}$. In this paper, GSA is used for determining the optimum size of the capacitor at the potential candidate bus. In this work, it is considered that a maximum of 3 capacitors can be placed for the reactive power compensation. By using GSA, the total compensation required for this system is $1661.7 \mathrm{kVAr}$, and it is placed at buses 6, 28, and 29 with the compensation values of $550.4 \mathrm{kVAr}, 562.8 \mathrm{kVAr}$, and 548.5 kVAr, respectively. The SLD of 33 bus RDS for Case 2 after incorporating the shunt capacitors is depicted in Fig. 6.

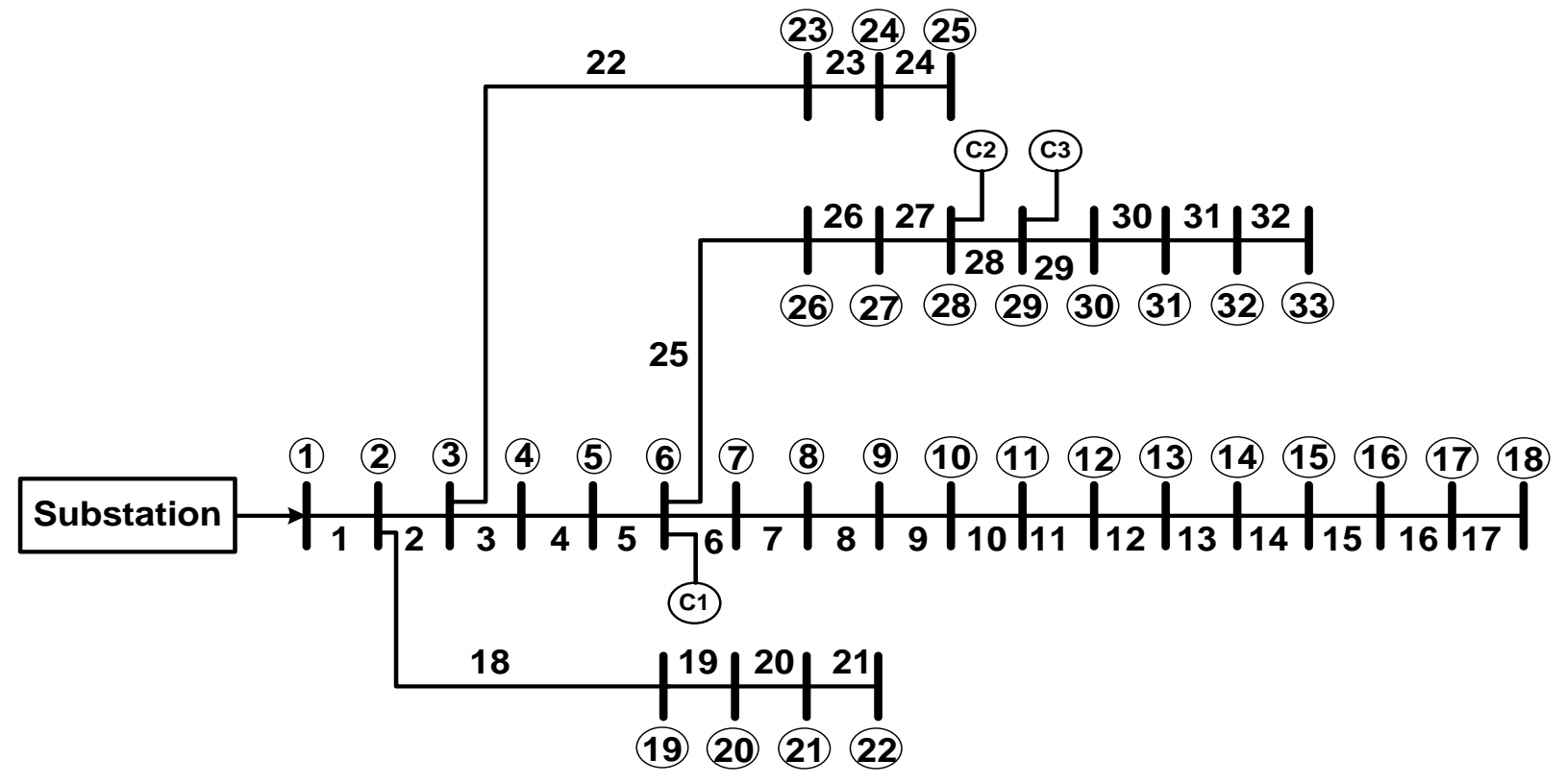

Fig. 6. SLD of 33 Bus RDS for Case 2 after Incorporating the Shunt Capacitors. 


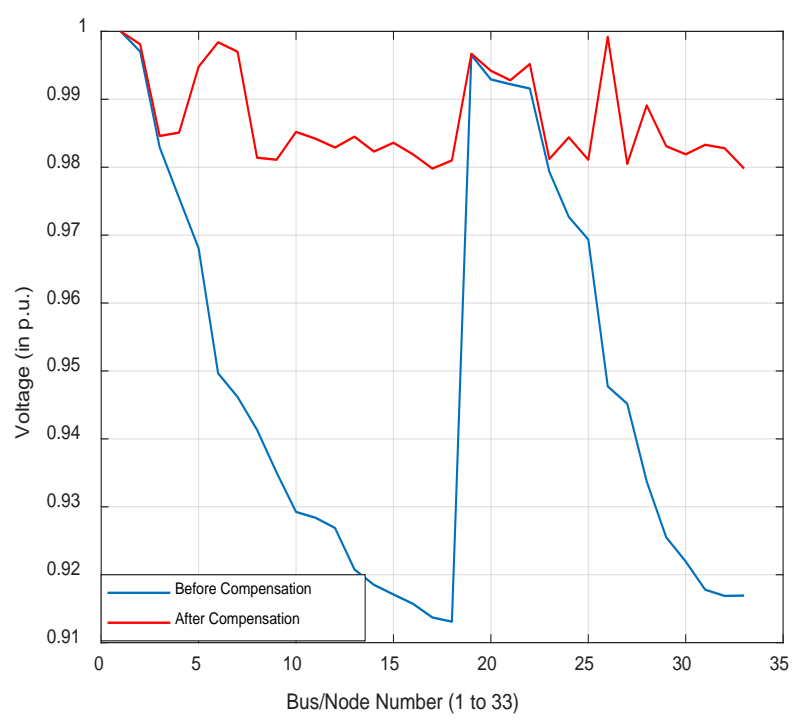

Fig. 7. Comparison of Node Voltages before and after Reconfiguration for a 33 Bus RDS.

The active power loss obtained in this case is $140.83 \mathrm{~kW}$ which resulted in the reduction of $30.51 \%$ compared to the case without any compensation. The results obtained with GSA are also compared with DEA, and the results are reported in Table II. Voltage profile of RDS has been improved after incorporating the shunt capacitors. Comparison of node voltages before and after the reconfiguration for 33 bus RDS is depicted in Fig. 7. Minimum voltage after installing the capacitors is found to be 0.9798 p.u.

\section{Case 3}

In this case, proposed optimization problem of RDS is solved by optimally allocating the DG units at various buses in the system. Table III presents the simulation results for Case 3 . In this case, DG of $835.8 \mathrm{~kW}$ is placed at bus $8,1105.6 \mathrm{~kW}$ is placed at bus 23, and $1084.9 \mathrm{~kW}$ is placed at bus 29 . Hence, the total size of DG is $3026.3 \mathrm{~kW}$. By optimally placing the DG units, the system power losses have been decreased to $84.62 \mathrm{~kW}$ from the base case loss of $202.66 \mathrm{~kW}$. Therefore, in this case, there is a loss reduction of $58.25 \%$ compared to base case losses. Fig. 8 depicts the improved voltage profiles for case 3 . The minimum voltage obtained in this case after DG allocation is 0.9742 p.u. which has been occurred at bus number 17 , whereas in the base case, the minimum voltage occurred is 0.9038 p.u. at bus number 18 .
TABLE III. SIMULATION RESULTS FOR 33 BUS RDS FOR CASES 3 AND 4

\begin{tabular}{|c|c|c|}
\hline & Case 3 & Case 4 \\
\hline $\begin{array}{l}\text { Tie switches opened for } \\
\text { reconfiguration }\end{array}$ & $\begin{array}{l}33,34,35,36, \\
37\end{array}$ & $7,9,14,32,37$ \\
\hline \multirow{3}{*}{$\begin{array}{l}\text { Bus number and DG size } \\
(\mathrm{kW})\end{array}$} & $\begin{array}{l}835.8 \mathrm{~kW} \text { at bus } \\
8\end{array}$ & $822.4 \mathrm{~kW}$ at bus 13 \\
\hline & $\begin{array}{l}1105.6 \mathrm{~kW} \text { at } \\
\text { bus } 23\end{array}$ & $1150.5 \mathrm{~kW}$ at bus 23 \\
\hline & $\begin{array}{l}1084.9 \mathrm{~kW} \text { at } \\
\text { bus } 29\end{array}$ & $983.2 \mathrm{~kW}$ at bus 30 \\
\hline Total DG size $(\mathrm{kW})$ & $3026.3 \mathrm{~kW}$ & $2956.1 \mathrm{~kW}$ \\
\hline \multirow{3}{*}{$\begin{array}{l}\text { Bus number and reactive } \\
\text { power compensation (kVAr) }\end{array}$} & --- & $560.5 \mathrm{kVAr}$ at bus 6 \\
\hline & --- & $565.2 \mathrm{kVAr}$ at bus 28 \\
\hline & --- & $540.8 \mathrm{kVAr}$ at bus 29 \\
\hline Total compensation (kVAr) & --- & $1666.5 \mathrm{kVAr}$ \\
\hline Power loss (kW) & $84.62 \mathrm{~kW}$ & $55.98 \mathrm{~kW}$ \\
\hline Power loss reduction & $58.25 \%$ & $72.38 \%$ \\
\hline Minimum voltage & $\begin{array}{l}0.9742 \text { pu at bus } \\
17\end{array}$ & $0.9802 \mathrm{pu}$ at bus 17 \\
\hline
\end{tabular}

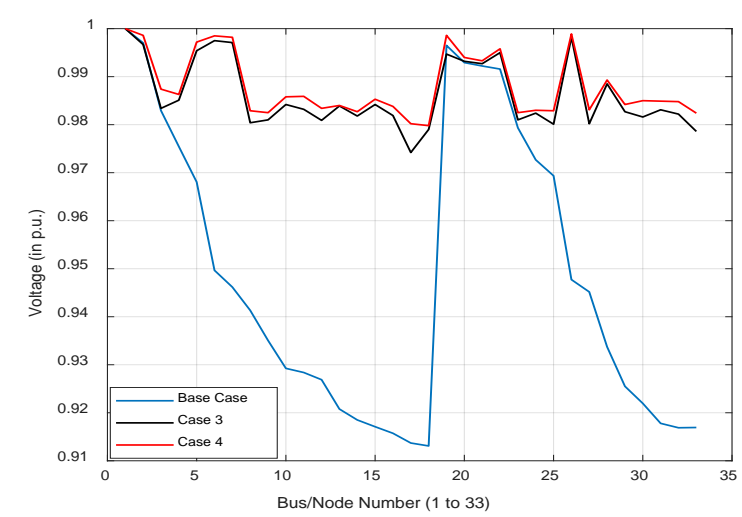

Fig. 8. Comparison of Node Voltages for the base Case, Case 3, and Case 4 for 33 Bus RDS.

\section{Case 4}

This case considers network reconfiguration, DG allocation, and reactive power compensation simultaneously for minimizing the system power losses. Table III presents the simulation results for Case 4. The opened tie-switches for ONR are 7, 9, 14, 32, and 37, and the system configuration for case 4 after the ONR has been depicted in Fig. 9. The total optimum DG size obtained is $2956.1 \mathrm{~kW}$. The buses 13, 23, and 30 are placed with DG units with capacities of $822.4 \mathrm{~kW}$, $1150.5 \mathrm{~kW}$, and $983.2 \mathrm{~kW}$, respectively. Here, the shunt capacitors are placed at buses 6,28 , and 29 with the reactive power compensation of $560.5 \mathrm{kVAr}, 565.2 \mathrm{kVAr}$, and 540.8 kVAr, respectively. 


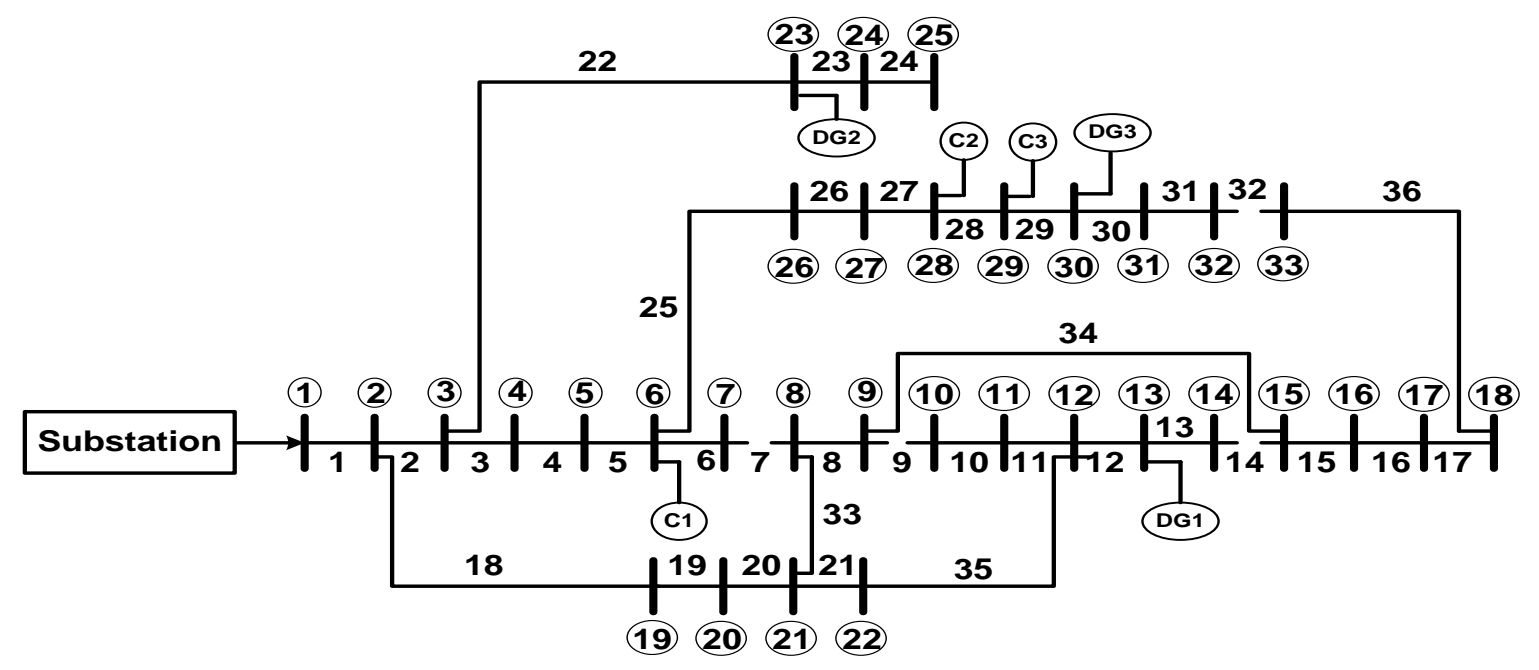

Fig. 9. Final Configuration of a 33 Bus RDS for Case 4 after Incorporating the Shunt Capacitors and DG Units.

The total optimum reactive power compensation required for Case 4 is $1666.5 \mathrm{kVAr}$. The obtained optimum loss is $55.98 \mathrm{~kW}$ which is $72.38 \%$ less when compared to base case power loss (i.e., $202.66 \mathrm{~kW}$ ). The voltage profile obtained in this case has been depicted in Fig. 8. From this figure, it can be observed that the voltage profile obtained in this case is better than all other cases studied in this work. Final configuration of a 33 bus RDS for Case 4 after incorporating the shunt capacitors and DG units has been depicted in Fig. 9. Minimum voltage occurred in this case after the ONR, DG allocation and reactive power compensation is 0.9802 p.u. at bus number 17, which has been improved from 0.9038 p.u. (i.e., base case).

\section{CONCLUSIONS}

This paper proposed an approach for the optimal allocation of distributed generations (DGs), shunt capacitors along optimal network reconfiguration using the meta-heuristicbased gravitational search algorithm (GSA). Here, the minimization of total active power losses is considered as an objective function, which will also enhance voltage profile in the system and hence reduces voltage deviation. The proposed problem has been implemented on the standard 33 bus radial distribution system (RDS). The obtained results show the improved voltage profile and reduced power losses in the system. The proposed work can also be extended to unbalanced RDSs and the optimal allocation of electric vehicles (EVs) can also be studied. Optimal allocation of energy storage systems (ESSs) along with FACTS devices such as D-STATCOM is scope for future research.

\section{ACKNOWLEDGMENT}

This research work was funded by "Woosong University's Academic Research Funding - 2021”.

\section{REFERENCES}

[1] V.A. Evangelopoulos, P.S. Georgilakis, N.D. Hatziargyriou, “Optimal operation of smart distribution networks: A review of models, methods and future research”, Electric Power Systems Research, vol. 140, pp. 95106, 2016.
[2] S. Haghifam, M. Dadashi, K. Zare, H. Seyedi, "Optimal operation of smart distribution networks in the presence of demand response aggregators and microgrid owners: A multi follower Bi-Level approach”, Sustainable Cities and Society, vol. 55, 2020.

[3] L.H. Macedo, J.F. Franco, M.J. Rider, R. Romero, "Optimal Operation of Distribution Networks Considering Energy Storage Devices", IEEE Transactions on Smart Grid, vol. 6, no. 6, pp. 2825-2836, Nov. 2015.

[4] S.R. Salkuti, "Feeder Reconfiguration in Unbalanced Distribution System with Wind and Solar Generation using Ant Lion Optimization”, International Journal of Advanced Computer Science and Applications, vol. 12, no. 3, pp. 31-39, 2021.

[5] H. Zhang, D. Zhao, C. Gu, F. Li, B. Wang, "Economic optimization of smart distribution networks considering real-time pricing", Journal of Modern Power Systems and Clean Energy, vol. 2, pp. 350-356, 2014.

[6] A.K. Fard, A. Khodaei, "Multi-objective optimal operation of smart reconfigurable distribution grids", AIMS Energy, vol. 4, no. 2, pp. 206221, 2016.

[7] H.M.A. Ahmed, M.H. Ahmed, M.M.A. Salama, "Network Reconfiguration for the Optimal Operation of Smart Distribution Systems”, IEEE Power \& Energy Society General Meeting, 2019, pp. 15.

[8] R. Afshan, J. Salehi, "Optimal operation of distribution networks with presence of distributed generations and battery energy storage systems considering uncertainties and risk analysis”, Journal of Renewable and Sustainable Energy, vol. 9, no. 1, 2017.

[9] S. Ouali, A. Cherkaoui, "Optimal Allocation of Combined Renewable Distributed Generation and Capacitor Units for Interconnection Cost Reduction”, Journal of Electrical and Computer Engineering, 2020.

[10] A. Uniyal, S. Sarangi, "Optimal network reconfiguration and DG allocation using adaptive modified whale optimization algorithm considering probabilistic load flow”, Electric Power Systems Research, vol. 192, 2021.

[11] R. Fathi, B. Tousi, S. Galvani, “A new approach for optimal allocation of photovoltaic and wind clean energy resources in distribution networks with reconfiguration considering uncertainty based on info-gap decision theory with risk aversion strategy", Journal of Cleaner Production, vol. 295, 2021.

[12] M.I. Pathan, M. Al-Muhaini, S.Z. Djokic, "Optimal reconfiguration and supply restoration of distribution networks with hybrid microgrids", Electric Power Systems Research, vol. 187, 2020.

[13] A.J. Nowdeh, M. Babanezhad, S.A. Nowdeh, A. Naderipour, H. Kamyab, Z.A. Malek, V.K. Ramachandaramurthy, "Meta-heuristic matrix moth-flame algorithm for optimal reconfiguration of distribution networks and placement of solar and wind renewable sources 
considering reliability”, Environmental Technology \& Innovation, vol. 20, 2020.

[14] S.R. Salkuti, "Multi-objective based Optimal Network Reconfiguration using Crow Search Algorithm," International Journal of Advanced Computer Science and Applications, vol. 12, no. 3, pp. 86-95, 2021.

[15] A.O. Salau, Y.W. Gebru, D. Bitew, "Optimal network reconfiguration for power loss minimization and voltage profile enhancement in distribution systems”, Heliyon, vol. 6, no. 6, 2020.

[16] S.R. Salkuti, "Optimal Allocation of DG and D-STATCOM in a Distribution System using Evolutionary based Bat Algorithm", International Journal of Advanced Computer Science and Applications, vol. 12, no. 4, pp. 360-365, 2021.

[17] K. Nagaraju, S. Sivanagaraju, T. Ramana, P.V. Prasad, "A novel load flow method for radial distribution systems for realistic loads", Electric Power Components and Systems, vol. 39, no. 2, pp. 128-141, 2011.

[18] I.B. Hamida, S.B. Salah, F. Msahli, M.F. Mimouni, "Optimal network reconfiguration and renewable DG integration considering time sequence variation in load and DGs”, Renewable Energy, vol. 121, pp. 66-80, 2018.

[19] S.R. Salkuti, "Optimal location and sizing of DG and D-STATCOM in distribution networks", Indonesian Journal of Electrical Engineering and Computer Science, vol. 16, no. 3, pp. 1107-1114, Dec. 2019.

[20] K. Mahmoud, N. Yorino, A. Ahmed, "Optimal Distributed Generation Allocation in Distribution Systems for Loss Minimization", IEEE Transactions on Power Systems, vol. 31, no. 2, pp. 960-969, Mar. 2016.

[21] R. Sanjay, T. Jayabarathi, T. Raghunathan, V. Ramesh, N. Mithulananthan, "Optimal Allocation of Distributed Generation Using Hybrid Grey Wolf Optimizer”, IEEE Access, vol. 5, pp. 14807-14818, 2017.

[22] K. Mahmoud, M. Lehtonen, "Simultaneous Allocation of Multi-Type Distributed Generations and Capacitors Using Generic Analytical Expressions”, IEEE Access, vol. 7, pp. 182701-182710, 2019.

[23] B.R. Pereira, G.R.M. da Costa, J. Contreras, J.R.S. Mantovani, “Optimal Distributed Generation and Reactive Power Allocation in Electrical Distribution Systems”, IEEE Transactions on Sustainable Energy, vol. 7, no. 3, pp. 975-984, July 2016.
[24] S. Ganguly, D. Samajpati, "Distributed Generation Allocation on Radial Distribution Networks Under Uncertainties of Load and Generation Using Genetic Algorithm”, IEEE Transactions on Sustainable Energy, vol. 6, no. 3, pp. 688-697, July 2015.

[25] S.R. Salkuti, Y.H. Lho, "Optimum Location of Voltage Regulators in the Radial Distribution Systems", International Journal of Emerging Electric Power Systems, vol. 17, no. 3, pp. 351-361, Jun. 2016.

[26] E. Rashedi, H. Nezamabadi-pour, S. Saryazdi, "GSA: A Gravitational Search Algorithm”, Information Sciences, vol. 179, no. 13, pp. 22322248, vol. 179, no. 13, 2009.

[27] R.K. Swain, N.C. Sahu, P.K. Hota, "Gravitational Search Algorithm for Optimal Economic Dispatch”, Procedia Technology, vol. 6, pp. 411-419, 2012.

[28] Z. Younes, I. Alhamrouni, S. Mekhilef, M. Reyasudin, “A memorybased gravitational search algorithm for solving economic dispatch problem in micro-grid”, Ain Shams Engineering Journal, 2021.

[29] B. Shaw, V. Mukherjee, S.P. Ghoshal, "Solution of reactive power dispatch of power systems by an opposition-based gravitational search algorithm", International Journal of Electrical Power \& Energy Systems, vol. 55, pp. 29-40, 2014.

[30] B. Venkatesh, R. Ranjan, "Optimal radial distribution system reconfiguration using fuzzy adaptation of evolutionary programming", International Journal of Electrical Power Energy Systems, vol. 25, no. 10, pp. 775-780, Dec. 2013.

[31] A. Bayat, A. Bagheri, R. Noroozian, "Electrical Power and Energy Systems Optimal siting and sizing of distributed generation accompanied by reconfiguration of distribution networks for maximum loss reduction by using a new UVDA-based heuristic method", International Journal of Electrical Power and Energy Systems, vol. 77, pp. 360-371, 2016.

[32] A.M. Imran, M. Kowsalya, "Electrical Power and Energy Systems A new power system reconfiguration scheme for power loss minimization and voltage profile enhancement using Fireworks Algorithm", International Journal of Electrical Power and Energy Systems, vol. 62, pp. 312-322, 2014. 